\title{
Cerebrospinal fluid gusher in incomplete partition type I anomaly
}

\author{
Levent Sennaroglu ${ }^{1} \mathbb{D}$
}

Received: 22 December 2020 / Accepted: 24 December 2020 / Published online: 13 January 2021

(c) The Author(s), under exclusive licence to Springer-Verlag GmbH, DE part of Springer Nature 2021

\section{Dear Editor,}

I would like to correct a comment in an article published in your journal. I read the article by Grover et al. [1] published in European Archives of Oto-Rhino-Laryngology. They cited one of my papers [2] and indicated that I reported no case of gusher in IP-I anomaly. In fact, if they had read the section of Cerebrospinal Fluid (CSF) Gusher on page 24 and examined Table I on page 26 carefully, they would have seen that I mentioned the gusher in IP-I in our cases. If Table I is examined carefully, they will notice that at the time of publication in 2010, we had operated 23 cases of IP-I, of which 9 had gusher while 14 had no CSF leakage. In their previous paper, the authors also cited our latest paper on the classification of inner ear malformations [3] which gives a $50 \%$ possibility of CSF gusher in IP-I on Table I, page 400.
As my name was involved in this article, I wanted to correct this wrong information.

\section{References}

1. Grover M et al (2020) Application of the new SMS system of cochleovestibular anomalies: our experience with nine cases of type III anomaly. Eur Arch Otorhinolaryngol. https://doi. org/10.1007/s00405-020-06114-4

2. Sennaroglu L (2010) Cochlear implantation in inner ear malformations - a review article. Cochlear Implants Int 11(1):4-41

3. Sennaroglu L, Bajin MD (2017) Classification and current management of inner ear malformations. Balkan Med J 34(5):397-411

Publisher's Note Springer Nature remains neutral with regard to jurisdictional claims in published maps and institutional affiliations.

This comment refers to the article available online at https://doi. org/10.1007/s00405-020-06114-4.

Levent Sennaroglu

lsennaroglu@gmail.com

1 Department of Otolaryngology, Hacettepe University

Medical Faculty, Ankara, Turkey 